\title{
"No touch" technique and hypothermic circulatory arrest for porcelain aorta in combined valve surgery
}

\author{
R Leyh", C Bening, C Schimmer, M Oezkur, A Gorski, K Hamouda \\ From World Society of Cardiothoracic Surgeons 25th Anniversary Congress, Edinburgh \\ Edinburgh, UK. 19-22 September 2015
}

\section{Background/Introduction}

Cardiac surgery in patients scheduled for combined single or multiple valve and CABG surgery with preoperatively undetected porcelain aorta is challenging. Different surgical strategies may address this problem. Abortion of the initial operation with subsequent interventional therapy and hypothermic circulatory arrest offer clampless treatment options in these patients.

\section{Aims/Objectives}

The aim of this retrospective study is to characterize patients with preoperatively undetected porcelain aorta scheduled for combined single or multiple valve and CABG surgery that were treated with hypothermic circulatory arrest during operation addressing the porcelain aorta and to describe the outcome.

\section{Method}

From $01 / 2011$ to $04 / 2015,19$ patients $(74.8 \pm 7.4$ years, $39 \%$ female) with preoperatively undetected porcelain aorta and combined single or multiple valve and CABG surgery were observed. 15 patients $(79 \%)$ presents with aortic valve pathology and CAD and 5 patients (26\%) with aortic valve pathology \pm CAD and mitral or tricuspid valve pathologies. In all patients the ascending aorta \pm hemiarch was replaced using circulatory arrest. The Euro Score II was $12.7 \pm 4.4 \%$.

\section{Results}

Mean cardiopulmonary bypass, cross clamp and hypothermic circulatory arrest times were, respectively, $140 \pm 48$ minutes, $96 \pm 37$ minutes and $11.9 \pm 3.3$ minutes. Bladder and tympanic temperature were, respectively, $27.9 \pm 2.3^{\circ} \mathrm{C}$ and $23.3 \pm 2.8^{\circ} \mathrm{C}$. The 30 day mortality was $10.5 \%(\mathrm{n}=2)$, Stroke occurred in 5.3\% ( $\mathrm{n}=1)$, renal failure in $15.8 \%(\mathrm{n}=$ $3)$, prolonged ventilation was necessary in $21 \%(n=4)$ and $10.5 \%(\mathrm{n}=2)$ had to be reoperated for bleeding, mean ICU stay was $4.4 \pm 2.4$ days. The mean length of hospital stay was $11.5 \pm 4.4$ days.

\section{Discussion/Conclusion}

These preliminary data indicates that hypothermic circulatory arrest with a "no touch" technique is a reasonable safe and reproducible surgical option in patients with preoperatively undetected porcelain aorta scheduled for combined single or multiple valve and CABG surgery. However, better preoperative diagnosis is necessary to select patients for different treatment strategies, surgery vs. interventional therapy and to conduct larger studies comparing the results of different treatment strategies in these high risk patients.

Published: 16 December 2015

doi:10.1186/1749-8090-10-S1-A173

Cite this article as: Leyh et al:: "No touch" technique and hypothermic circulatory arrest for porcelain aorta in combined valve surgery. Journal of Cardiothoracic Surgery 2015 10(Suppl 1):A173. 